\title{
Galangin Alleviates Liver Ischemia- Reperfusion Injury in a Rat Model by Mediating the PI3K/AKT Pathway
}

\author{
Yang Lia Liquan Tong $^{\mathrm{a}} \quad$ Jingyan Zhang ${ }^{\mathrm{a}} \quad$ Yafeng Zhang $^{\mathrm{b}} \quad$ Feng Zhang $^{\mathrm{a}}$ \\ aDepartment of General Surgery, the Fifth Affiliated Hospital of Harbin Medical University, Daqing, \\ bDepartment of Psychiatry, the Seventh people's Hospital of Cixi City, Ningbo, China
}

\section{Key Words}

Liver ischemia-reperfusion injury • Galangin • PI3K/AKT • Cell apoptosis

\begin{abstract}
Background/Aims: Liver ischemia-reperfusion (I/R) injury is a pathological process that often occurs during liver and trauma surgery. There are numerous causes of liver I/R injury, but the mechanism is unknown. Galangin (GA) is a flavonoid, a polyphenolic compound widely distributed in medicinal herbs that has anti-inflammatory, antioxidant, and antitumor activity. This study evaluated the protective effect of GA on hepatic I/R injury. Methods: An I/R model was created in male Wistar rats by clamping the hepatoportal vein, hepatic artery and hepatic duct for $30 \mathrm{~min}$ followed by reperfusion for $2 \mathrm{~h}$. A hypoxia/restoration $(\mathrm{H} / \mathrm{R})$ model was established in buffalo rat liver (BRL) cells by hypoxia for $4 \mathrm{~h}$ followed by normoxic conditions for $10 \mathrm{~h}$. The extent of liver injury was assayed by serum ALT/AST, hepatic histology, and MPO activity. Oxidative stress was assayed by serum superoxide dismutase (SOD), catalase (CAT), glutathione (GSH) and malondialdehyde (MDA). Expression of apoptosis-related proteins in BRL cells was assayed in western blots. Expression of AKT and $\mathrm{p}$-AKT proteins in vivo and vitro were assayed in western blots. Results: GA significantly decreased ALT/AST expression, reversed changes in oxidative stress markers induced by $\mathrm{I} / \mathrm{R}$, and mediated caspase- 3 activity expression of apoptosis-related proteins in vivo and in vitro. Methylthiazol tetrazolium (MTT) assay, flow cytometry, and Hoechst 33258 staining confirmed that GA inhibited apoptosis of BRL cells. GA also increased the expression of phosphorylated AKT after H/R. Conclusion: GA reduced liver I/R injury both in vivo and vitro and inhibited BRL cell apoptosis. PI3K/AKT signaling have been involved. GA may protect against liver I/R and be a potential therapeutic candidate.




\section{Cellular Physiology Cell Physiol Biochem 2018;51:1354-1363 and Biochemistry Published \begin{tabular}{l|l} 
DOI: 10.1159/000495553 & (c) 2018 The Author(s). Published by S. Karger AG, Basel \\
www.karger.com/cpb
\end{tabular} \\ Li et al.: Galangin Protects Liver Ischemia-Reperfusion Injury}

\section{Introduction}

Liver ischemia-reperfusion (I/R) injury is a pathophysiological process common to liver dysfunction and failure after hepatic trauma, resection, transplantation, and circulatory shock [1]. Since the introduction of vascular control techniques in hepatic surgery, liver I/R has been recognized as one of the key elements that lead to postoperative higher morbidity and mortality [2]. I/R-induced liver injury involves multiple complex mechanisms, including anaerobic metabolism, mitochondrial damage, oxidative stress, endoplasmic reticulum stress, intracellular calcium overload, Kupffer cell activation, neutrophil infiltration, and production of cytokines and chemokines [1, 3, 4]. Ischemic preconditioning (IPC) has been considered to be a powerful endogenous intervention mechanism for protection against I/R [5]. However, I/R-induced liver injury still remains an important clinical problem despite the recent improvements in treatment conditions and surgical techniques.

Liver I/R mainly includes the following dynamic processes [6]. Adenosine triphosphate (ATP) depletion interferes with the cellular energy-dependent metabolic and transport processes [6, 7]. The reperfusion process consists of two phases: in the initial phase, activated resident macrophages of the liver, the Kupffer cells, induce oxidative stress mainly by reactive oxygen species (ROS) generation and, in the later phase, recruited neutrophils release inflammatory mediators which can cause cell apoptosis or death $[4,8]$. So inhibition of cell apoptosis may be of clinical importance in managing I/R injury.

Specific morphological characteristics and energy-dependent biochemical mechanisms have been associated with programmed cell death or apoptosis [9], and apoptotic pathways are often induced by upstream activators including PI3K/AKT/mTOR signaling, proapoptotic proteins in the Bcl-2 family, cellular stress stimuli, and hypoxia [10]. PI3K/AKT signaling is a classic anti-apoptosis pathway and its involvement in the process of liver I/R injury has been reported [11-13].

Galangin (GA), is a naturally occurring flavonoid compound that can be isolated from the rhizome of Alpinia galangal. It is used for cooking in Asian countries and as an herbal treatment of diabetes, cough, colds, stomach ache, and diarrhea. GA was found to reduce oxidative damage and inflammatory changes in fructose-fed rat liver [14]. The anticancer effects of GA have been shown in melanoma, leukemia, colon cancer cell lines [15-17]. Considering its antioxidant and anti-inflammatory activities, we hypothesized that GA can protect against liver I/R injury, possibly by regulating PI3K/AKT signaling.

\section{Materials and Methods}

\section{Hepatic I/R injury model}

Male Wistar rats weighing 200-240 g from the Animal Research Center at Harbin Medical University, Harbin, China were used. The study was approved by the Experimental Animal Ethics Committee of Harbin Medical University. Hepatic ischemia was induced as previously described [18]. Briefly, Wistar rats were anesthetized with sodium pentobarbital combined with methoxyflurane (inhalation) anesthesia, and a midline laparotomy was performed to isolate and clamp the portal vein, hepatic arterial, and hepatic duct. After $30 \mathrm{~min}$, the clip was removed to initiate hepatic reperfusion, which was maintained for $2 \mathrm{~h}$. Experimental animals were randomly allocated to three groups of ten rats each, controls (laparotomy only), laparotomy with I/R, and I/R with intraperitoneal injection of $100 \mu \mathrm{mol} / \mathrm{kg} \mathrm{GA}$ (Sigma) (I/R+GA). GA was intraperitoneally injected $1 \mathrm{~h}$ before ischemia. When the experimental procedures were completed, blood was collected by cardiac puncture for serum analysis and liver tissue was harvested; both were stored at $-80^{\circ} \mathrm{C}$ until used. 


\section{Cellular Physiology Cell Physiol Biochem 2018;51:1354-1363 \begin{tabular}{ll|l} 
and BiOChemistry Published online: 27 November 2018 & $\begin{array}{l}\text { (c) } 2018 \text { The Author(s). Published by S. Karger AG, Basel } \\
\text { www.karger.com/cpb }\end{array}$ \\
\hline
\end{tabular}}

Li et al.: Galangin Protects Liver Ischemia-Reperfusion Injury

\section{Blood and tissue analysis}

Serum concentrations of alanine aminotransferase (ALT) and aspartate aminotransferase (AST) were assayed by an automated biochemical analyzer (Toshiba, Tokyo, Japan). Serum SOD and CAT activity (U/ $\mathrm{mg}$ ) and liver tissue GSH (mg/g) and MDA (nmol/mg) were assayed using commercial kits (Jiancheng Biotechnology, Nanjing, China) following the manufacturer's instructions. The activity of myeloperoxidase (MPO), an enzyme specific to polymorphonuclear neutrophils, was assayed in liver tissue using a commercial kit (Jiancheng Biotechnology, Nanjing, China) following the manufacturer's instructions. Caspase-3 activity was assayed in liver tissue using a commercial kit (Beyotime, Shanghai, China) following the manufacturer's instructions.

\section{Histopathology}

Liver sections were fixed in 4\% paraformaldehyde overnight, dehydrated, cleared, and embedded in paraffin. The tissues were then sectioned at $5 \mu \mathrm{m}$ and stained with hematoxylin and eosin (H\&E) for examination by light microscopy.

\section{Cell culture}

The Buffalo rat liver (BRL) cell line was purchased from the Cell Bank of the Type Culture Collection of the Chinese Academy of Sciences (Shanghai, China). The cells were cultured in DMEM (Dulbecco's modified Eagle's medium) with $10 \%$ fetal bovine serum and 1\% penicillin and streptomycin at $37^{\circ} \mathrm{C}$ and $5 \% \mathrm{CO}$. To model hypoxia/restoration (H/R), cells were incubated in hypoxic conditions with a gas mixture of $92 \%$ $\mathrm{N} 2,5 \% \mathrm{CO}$, and $3 \% \mathrm{O}_{2}$ for $4 \mathrm{~h}$ and then in normal culture conditions for $10 \mathrm{~h}$ as previously described [19]. Before use, BRL cells were rested for $24 \mathrm{~h}$ in DMEM without serum and then divided into four treatment groups. These were controls, H/R, GA added at the beginning of H/R treatment (H/R + GA), and GA plus 25 mM LY294002, a phosphatidylinositol 3-kinase inhibitor [20], added $2 \mathrm{~h}$ before the addition of GA at the beginning of $\mathrm{H} / \mathrm{R}$ treatment $(\mathrm{H} / \mathrm{R}+\mathrm{GA}+\mathrm{LY})$.

\section{Apoptosis assay}

BRL cells apoptosis can be quantitatively analyzed by detection of DNA fragmentation via a fluorescence assay based on terminal deoxynucleotidyl transferase (TdT)-mediated dUTP nick-end labeling (TUNEL) technique (Beyotime Institute of Biotechnology, China) as previously described [21].

\section{Methylthiazol tetrazolium (MTT) assay}

BRL cells were seeded into a 96-well plate and incubated with GA of different doses.

Next, BRL cells were cultured in hypoxia for $4 \mathrm{~h}$ and then in normal culture conditions for $10 \mathrm{~h}$. Medium containing $0.5 \%$ MTT was added, the supernatant was removed after culture at $37^{\circ} \mathrm{C} 4 \mathrm{~h}$, and $150 \mu \mathrm{l} /$ well DMSO was added at room temperature for $10 \mathrm{~min}$. Absorbance at $490 \mathrm{~nm}$ was then read using a standard microplate reader.

\section{Hoechst 33258 staining}

Hoechst 33258 staining was used to detect morphological evidence of cell apoptosis. After treatment, BRL cells were stained with Hoechst $33258(1 \mu \mathrm{g} / \mathrm{mL})$ for $30 \mathrm{~min}$ in the dark. Nuclear morphology was evaluated by fluorescence microscopy at $350 \mathrm{~nm}$ and $460 \mathrm{~nm}$.

\section{Annexin V-FITC apoptosis assay}

An Annexin V-FITC apoptosis detection kit (Beyotime) was used to determine apoptotic ratios. Briefly, BRL cells were collected and washed three times with cold PBS, resuspended in $195 \mu \mathrm{L}$ of Annexin V-FITC binding buffer, incubated with $5 \mu \mathrm{L}$ Annexin V-FITC and $10 \mu \mathrm{L}$ propidium iodide for 15 min at room temperature in the dark. The percentage of apoptotic cells was assayed immediately by flow cytometry.

\section{Western blot assay}

Liver samples were homogenized in a micro-tissue grinder in ice cold storage buffer (Tris $50 \mathrm{mM}, \mathrm{pH}$ 7. 4, $\mathrm{NaCl} 150 \mathrm{mM}$, Triton X-100\%, EDTA $1 \mathrm{mM}$, and PMSF $2 \mathrm{mM}$ ) and then centrifuged at $13,500 \mathrm{~g}$ at $4 \stackrel{\circ}{\circ} \mathrm{C}$ for $15 \mathrm{~min}$. The supernatants were collected and used for western blot assays. BRL cells were suspended in lysis buffer (Tris 50 mM, pH 7.4, NaCl 150 mM, Triton X-100\%, EDTA 1 mM, and PMSF 2 mM) containing phosphatase inhibitor. The lysates were sonicated, centrifuged at $13,500 \mathrm{~g}$ at $4^{\circ} \mathrm{C}$ for $15 \mathrm{~min}$, the insoluble fraction was discarded and the supernatants were collected and used in the western blot assays. The protein concentration was determined by bicinchoninic acid assay and $10 \mu \mathrm{L}$ aliquots containing $20 \mu \mathrm{g}$ total cell proteins were separated by $10 \%$ sodium dodecyl sulfate-polyacrylamide gel electrophoresis (SDS-PAGE) and then transferred to nitrocellulose membranes as previously described [22]. The membranes were blocked at room temperature for $2 \mathrm{~h}$ in TBST and $0.1 \%$ Tween 20 containing 5\% nonfat dry milk. The membranes were 
incubated overnight at $4^{\circ} \mathrm{C}$ with antibodies against Cleaved Caspase-3 (1:200), Bax (1:100), Bcl-2 (1:200, all from Boster, Wuhan, China), Akt (1:500), phosphorylated Akt (Ser473, 1:500, both from Beyotime), NLRP3 (1:1000, Abcam) and $\beta$-actin (1:1000, Boster). After three washes with TBST, the membranes were incubated with horseradish peroxidase-conjugated secondary antibodies at room temperature for $1 \mathrm{~h}$. Membranes were developed with enhanced chemiluminescence reagents (ECL; Applygen Technology Inc. Beijing, China) and the final results were obtained by X-ray exposure.

\section{Statistical analysis}

The composite data were expressed as mean \pm SD. Statistical analysis was performed with one-way ANOVA followed by Dunnett's test. Differences were considered to be significant at $\mathrm{P} \leq 0.05$.

\section{Results}

\section{GA decreased I/R-induced liver injury}

We treated I/R groups with different concentrations of GA and detected the ALT and AST level (Fig. 1A-B). Finally, we chose $100 \mu \mathrm{mol} / \mathrm{kg}$ as the most suitable concentration. As shown in Fig. 2A and B, ALT and AST levels were higher in the I/R than in the control group after $2 \mathrm{~h}$ reperfusion. GA significantly decreased the I/R-induced peaks in ALT and AST level. The arrangement of liver plates was disturbed and sinusoid tissue congestion was observed in liver tissue from the I/R group but not in tissue from sham operated controls at $10 \times$ magnification. Vacuole formation, cellular swelling, inflammatory cells, and lymphocyte infiltration were evident in I/R but not control tissue. The I/R-related changes were reduced in tissue from $\mathrm{I} / \mathrm{R}+\mathrm{GA}$

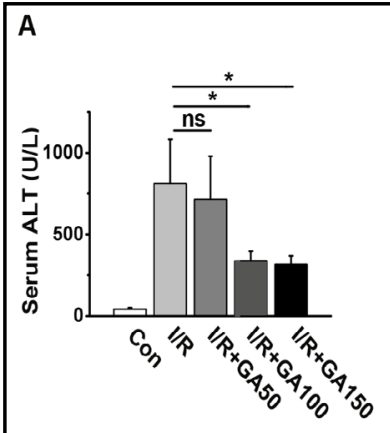

B

Fig.1. Serum ALT (A) and AST (B) levels in I/R rats. Values are means $\pm \mathrm{SD}(\mathrm{n}=6) .{ }^{*} \mathrm{P}<0.05$. treated animals (Fig. 2C). MPO activity, which indicates neutrophil activity, was increased after reperfusion in $\mathrm{I} / \mathrm{R}$ group compared with controls. GA reduced MPO activity (Fig. 2D).
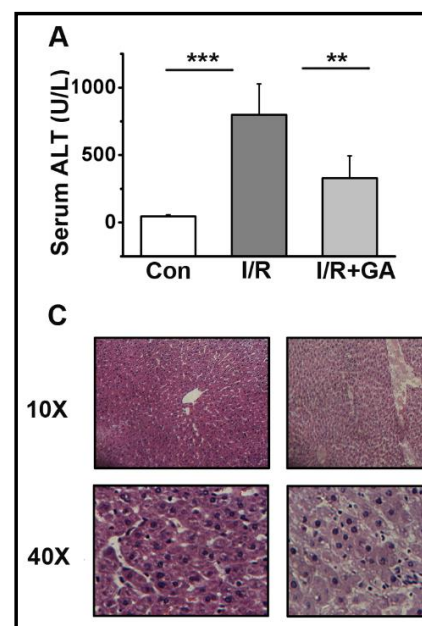

Con

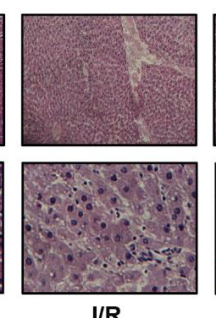

I/R

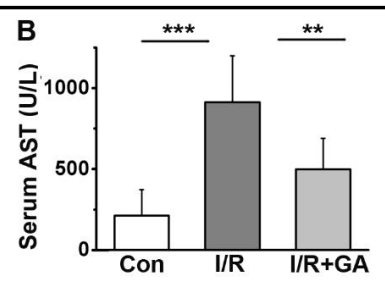

D
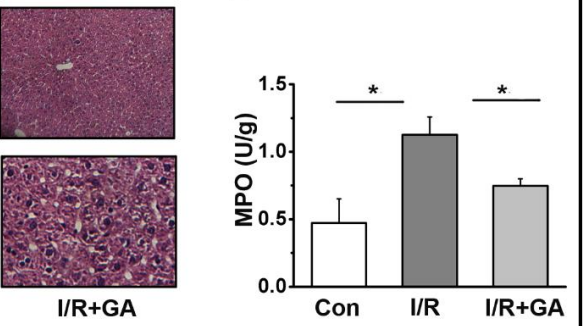

Fig. 2. GA decreased liver injury induced by I/R. Serum ALT (A) and AST (B) were assayed after liver ischemia and $2 \mathrm{~h}$ of reperfusion with or without intraperitoneal injection of GA. (C) Representative hematoxylin-eosin (H\&E) stained liver sections from Controls, I/R, and I/R+GA groups. Upper panel, $\times 10$; lower panel, $\times 40$. (D) MPO activity after $2 \mathrm{~h}$ reperfusion. Values are means $\pm \mathrm{SD}$ $(\mathrm{n}=6) .{ }^{*} \mathrm{P}<0.05 ;{ }^{* *} \mathrm{P}<0.01$. 
GA reduced oxidative stress in $I / R$ rats

As shown in Fig. 3A, I/R injury appreciably reduced SOD activity in the I/R group compared with the controls. SOD activity was significantly increased by GA treatment. Similarly, CAT activity was significantly decreased after reperfusion compared with the controls, but activity was not as strongly affected in the I/R+GA group. (Fig. 3B). GSH concentration was significantly lower in the I/R than in the control group and was significantly higher in the I/ $\mathrm{R}+\mathrm{GA}$ than in the I/R group (Fig. 3C). The MDA concentration was significantly higher in the $\mathrm{I} / \mathrm{R}$ than in the control group and was significantly lower in the I/R+GA than in the I/R group (Fig. 3D).

In vivo, GA has an antiapoptotic effect on liver cells

To determine effect of GA on hepatocellular apoptosis induced by IR, we assayed caspase- 3 activity in ischemic livers. Caspase- 3 activity was markedly elevated in rats in the I/R group; however, GA treatment reduced Caspase-3 activity (Fig. 4A). We also assayed hepatocellular apoptosis in western blots, which showed that the expression of apoptosisrelated proteins was affected by I/R, and that GA had an antiapoptotic effect (Fig. 4B-D). We also found that the expression of inflammasome complex NLRP3 was increased in the I/R group; however, GA treatment reduced the expression of NLRP3 (Fig. 4E). We used TUNEL assay to detect the BRL cells apoptosis. The number of apoptotic BRL cells increased in I/R compared with the normal group. However, GA inhibited BRL cells apoptosis induced by I/R (Fig. 4F). A similar result was obtained with Hoechst 33258 staining (Fig. 4G).

\section{GA enhanced BRL survival after $H / R$ treatment}

Exposure to $\mathrm{H} / \mathrm{R}$ conditions significantly decreased the viability of BRL cells compared with controls. However, when the cells were cultured with GA $(0.5,1,2,4,8 \mu \mathrm{M})$ before exposure to H/R conditions, viability was improved compared with H/R alone. As shown in Fig. 5, GA enhanced the viability of BRL cells at a concentration of $4 \mu \mathrm{M}$.

GA inhibited H/R-induced apoptosis of BRL cells by activating the PI3K/AKT pathway

As shown in Fig. 6A, apoptotic BRL cells stained with Hoechst 33258 appeared bright blue with filaments in the cell nucleus. Most apoptotic BRL cells were in the H/R group. GA had a protective effect on cell apoptosis that was decreased by the AKT pathway inhibitor LY294002. As shown in Fig. 6B, flow cytometry quadrants Q2 and Q4 are associated with cell apoptosis. The percentage of apoptotic cells increased with H/R treatment. GA decreased the apoptosis percentage, but the effect of GA was decreased by LY294002. To determine whether the PI3K/AKT pathway was involved in GA-mediated apoptosis of H/R BRL cells, we assayed p-Akt protein and AKT protein expression. Compared with controls, p-Akt expression was decreased by $H / R$ treatment, increased in the H/R+GA group compared with the H/R group,

Fig. 3. Serum SOD (A), CAT (B), GSH (C), and MDA (D) levels. Values are means $\pm \mathrm{SD}(\mathrm{n}=6) . * \mathrm{P}<0.05$ ** $\mathrm{P}<0.01$.

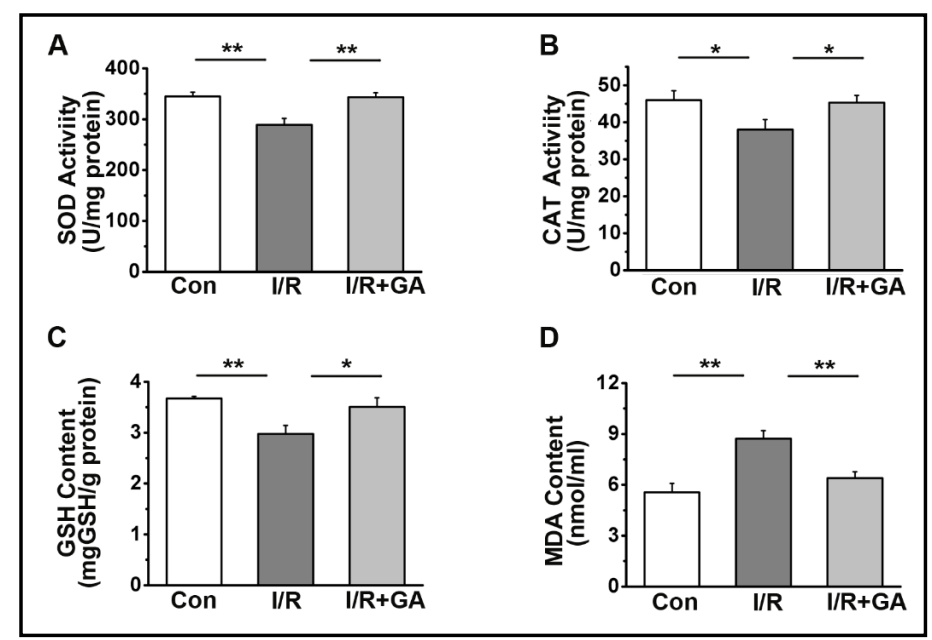


Fig. 4. In vivo, GA inhibited apoptosis induced by I/R. (A) Caspase-3 activity. (BE) Western blot assay of Bax, Bcl-2, Cleaved Caspase-3, NLRP3 and $\beta$-actin. (F) Apoptosis of BRL cells evaluated by TUNEL assay. (G) Morphology of BRL cells evaluated by Hoechst 33258 staining. Values are means \pm SD. $(n=5)$. $* \mathrm{P}<0.05 ; \quad * * \mathrm{P}<0.01$; $* * * \mathrm{P}<0.001$.

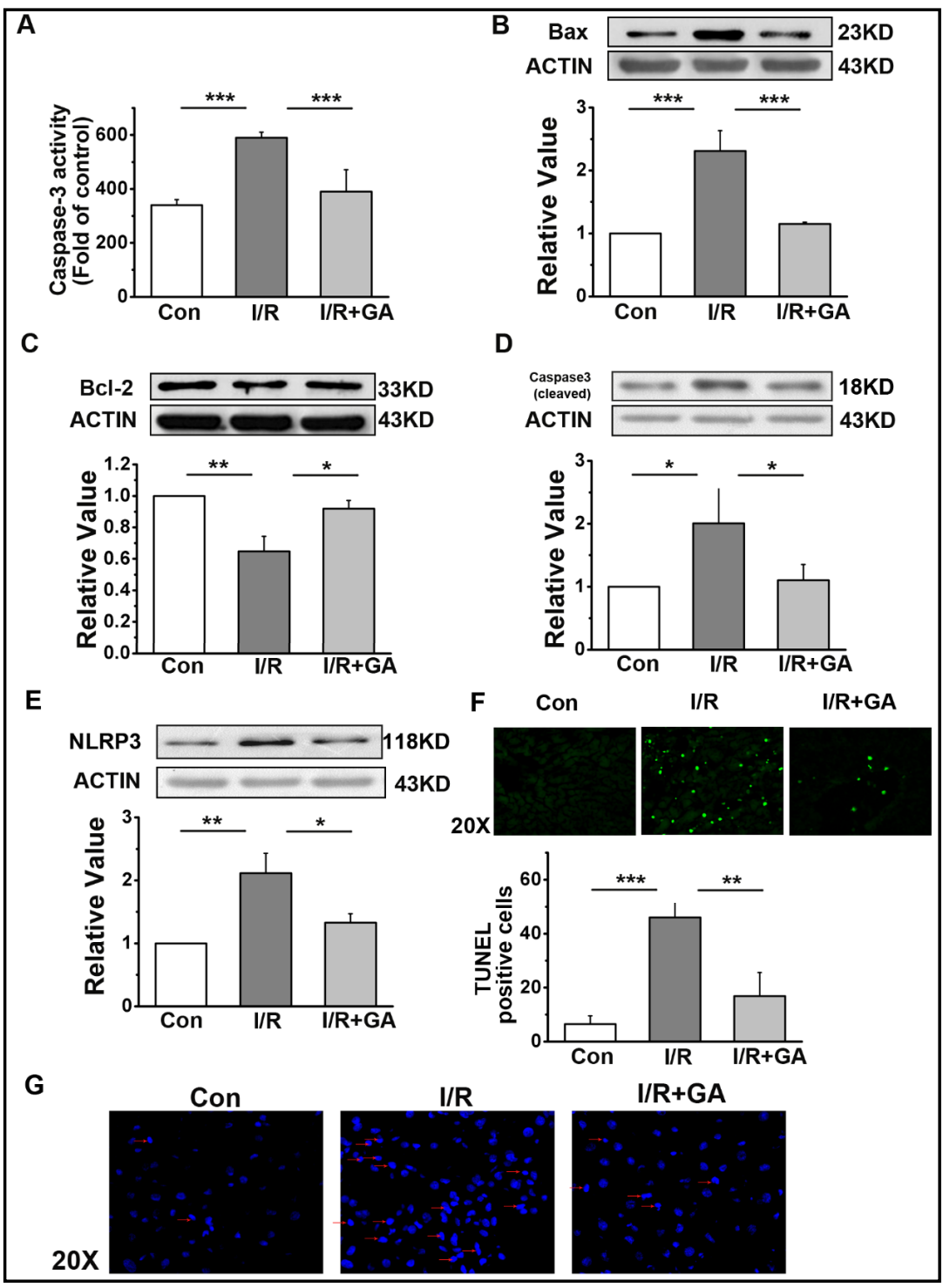

Fig. 5. MTT assay of cell viability after H/R. Normal BRL cells (control), BRL cells exposed to $H / R$, and BRL cells exposed to $H / R$ and treated with GA $(0.5,1,2,4$, or $8 \mu \mathrm{M})$. Values are means $\pm \mathrm{SD}$ $(\mathrm{n}=5)$. ${ }^{* *} \mathrm{P}<0.01$ vs. the control group; \#\#P $<0.01$; \#\#\#P $<0.001$ vs. $\mathrm{H} / \mathrm{R}$ group.

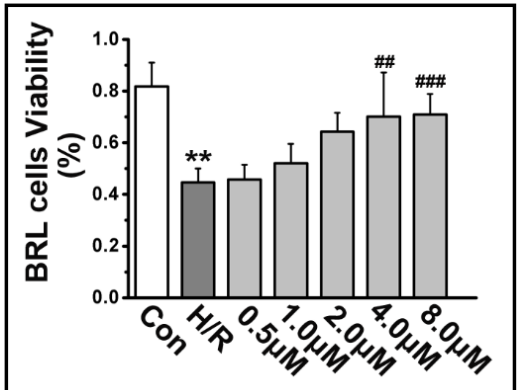

and decreased in the $\mathrm{H} / \mathrm{R}+\mathrm{GA}+\mathrm{LY}$ group compared with the H/R+GA group. Akt expression did not change (Fig. 7A). Changes in the expression of apoptosis-related proteins were consist with the above results (Fig. 7B-D). We assayed NLRP3 protein expression in vitro. Compared with controls, NLRP3 expression was increased by H/R treatment, decreased in the $\mathrm{H} / \mathrm{R}+\mathrm{GA}$ group compared with the H/R group, and increased in the H/R+GA+LY group compared with the $\mathrm{H} / \mathrm{R}+\mathrm{GA}$ group. (Fig. 7E). We also detected the protein expression of p-Akt and AKT in vivo and found that liver I/R decreased the expression of p-Akt, while GA increased the expression of p-Akt (Fig. 8). 


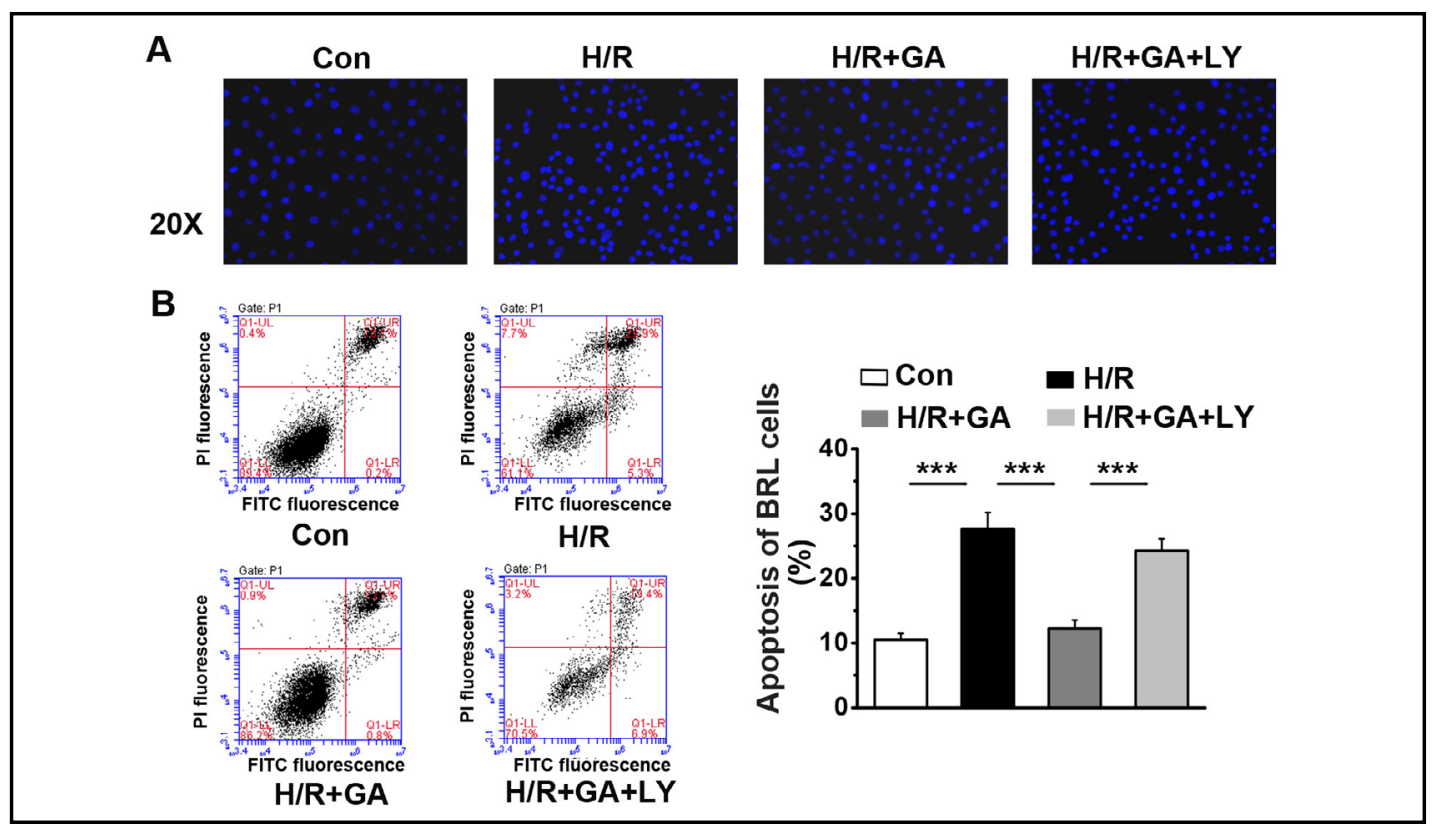

Fig. 6. In vitro, GA inhibited apoptosis induced by I/R. (A) Morphology of BRL cells evaluated by Hoechst 33258 staining. (B) Apoptosis of BRL cells assayed by flow cytometry. Values are means \pm SD (n=5). ${ }^{* * * P}$ $<0.001$.

Fig. 7. Expression of AKT, P-AKT (A), Bax (B), Bcl2 (C), Cleaved Caspase-3 (D) and NLRP3 (E) by western blot assay. Values are means \pm SD $(\mathrm{n}=5)$. ${ }^{*} \mathrm{P}<0.05$; ${ }^{* *} \mathrm{P}<0.01$. Con, normal; H/R, BRL cells exposed to hypoxia; $H / R+G A$, BRL cells exposed to hypoxia and treated with GA; H/R+GA+LY, BRL cells exposed to hypoxia and treated with GA+LY.

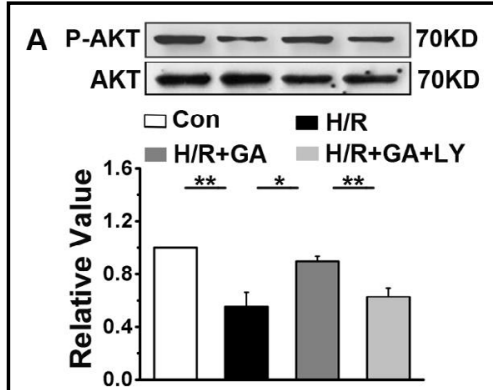

C
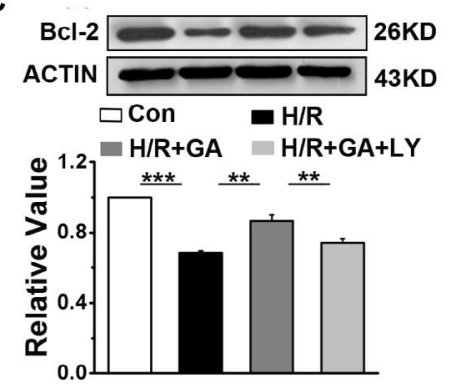

E

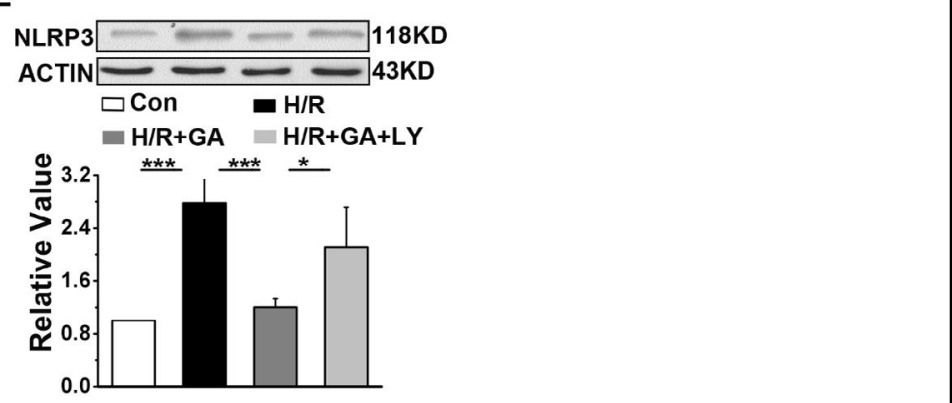

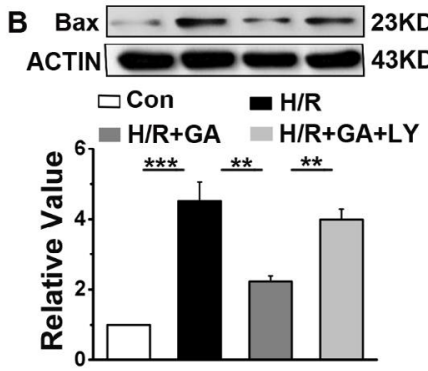

D
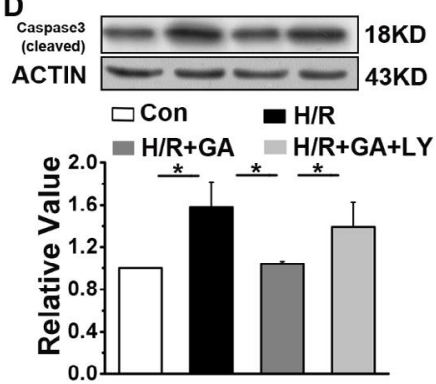


\section{Cellular Physiology Cell Physiol Biochem 2018;51:1354-1363

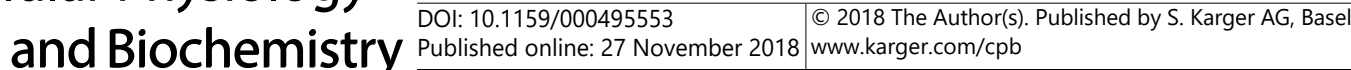 \\ Li et al.: Galangin Protects Liver Ischemia-Reperfusion Injury}

\section{Discussion}

GA is a potent free radical scavenger [23] and is known to have anti-inflammatory, antioxidant and anticancer effects in several tissues and organs [24, 25]. This study found that GA had a protective effect on liver I/R. GA significantly decreased high ALT/AST levels induced by $\mathrm{I} / \mathrm{R}$ and mediated oxidative stress in an I/R rat model. GA also inhibited liver damage in I/R rats. In vitro, the MTT assay, Hoechst33258 staining, annexin V-FITC apoptosis assay and western blots consistently showed that GA decreased apoptosis of BRL cells. The results also showed that the PI3K/AKT pathway was involved in GA inhibition of liver I/R injury. Overall, the study supports the potential of GA for clinical prevention of liver I/R injury.

I/R injury is caused by a complex series of events including cell death resulting from oxygen deprivation and adenosine triphosphate depletion during ischemia and subsequent activation of cells of the innate immune system by inflammatory responses during reperfusion [26]. In the process of I/R injury, redox balance is dysregulated and the normal functions and integrity of tissues are damaged, resulting in the accumulation of reactive oxygen species (ROS). The accumulation of ROS and oxidative stress are the most common type of liver ischemia-reperfusion injury mechanism [27]. Antioxidants such as SOD, CAT, and glutathione (GSH) peroxidase are the first line of defense against oxidative stress. These enzymes catalyze the oxidation of oxygen into inactive substances [28]. Normally, the negative effects of superoxides are suppressed by SOD, which transforms them into hydrogen peroxide $[29,30]$. Under the conditions associated with $I / R$, these defense mechanisms are impaired, and hydrogen peroxide is split into hydrogen and oxygen free radicals that damage many types of biological molecules, including amino acids, membrane transport proteins and nucleic acids [31]. GSH is a key antioxidant, and the increase of intracellular GSH concentration contributes to endothelial cell resistance to oxidative damage. CAT is an oxidoreductase that catalyzes the reduction of hydrogen peroxide into water and oxygen and protects cells against damage caused by ROS induced by I/R [32,33]. This study showed that GA mediated the above mentioned oxidative stress markers associated with I/R and had a protective effect against the injury caused by oxidative stress.

Apoptosis of hepatocytes and sinusoidal endothelial cells is an important cause of liver I/R injury [34]. Many factors activate apoptotic cascade proteins and extensive evidence indicates that caspase 3 apoptosis "killers" are involved in I/R injury [35]. The Bcl-2 protein family also plays an important role in intrinsic hepatocyte apoptosis, especially Bcl-2 and Bax. The Bcl-2/Bax ratio determines cell fate in response to an apoptotic stimulus [36, 37]. This study confirmed that in vivo or in vitro, GA regulated the expression of apoptosis-related proteins after I/R. These data indicate that GA has a protective effect on mitochondrial apoptosis caused by liver I/R. Whether GA plays a role in apoptosis caused by death receptors awaits further investigation.

\section{Conclusion}

In this study, we used the PI3K/AKT pathway inhibitor LY294002 to treat BRL cells, and consistent with the previous results, $\mathrm{p}$-AKT expression was decreased after $\mathrm{H} / \mathrm{R}$ treatment. GA thus protected liver I/R partly by PI3K/AKT signaling, but the specific regulation mechanism needs further investigation. 


\section{Cellular Physiology Cell Physiol Biochem 2018;51:1354-1363 \begin{tabular}{ll|l} 
and Biochemistry & $\begin{array}{l}\text { DOI: 10.1159/000495553 } \\
\text { Published onlIne: } 27 \text { November } 2018\end{array}$ & $\begin{array}{l}\text { (c) } 2018 \text { The Author(s). Published by S. Karger AG, Basel } \\
\text { www.karger.com/cpb }\end{array}$
\end{tabular}}

Li et al.: Galangin Protects Liver Ischemia-Reperfusion Injury

\section{Disclosure Statement}

The authors declare to have no competing interests.

\section{References}

$>1$ Jaeschke H: Molecular mechanisms of hepatic ischemia-reperfusion injury and preconditioning. American journal of physiology Gastrointestinal and liver physiology 2003;284:G15-26.

2 Serracino-Inglott F, Habib NA, Mathie RT: Hepatic ischemia-reperfusion injury. American journal of surgery 2001;181:160-166.

-3 Shah KA, Shurey S, Green CJ: Characterization of apoptosis in intestinal ischaemia-reperfusion injury--a light and electron microscopic study. International journal of experimental pathology 1997;78:355-363.

4 Noda T, Iwakiri R, Fujimoto K, Matsuo S, Aw TY: Programmed cell death induced by ischemia-reperfusion in rat intestinal mucosa. The American journal of physiology 1998;274:G270-276.

5 Kong R, Gao Y, Sun B, Chen H, Wang G, Wang X, Zhu H, Pan S, Xue D, Jiang H: The strategy of combined ischemia preconditioning and salvianolic acid-b pretreatment to prevent hepatic ischemia-reperfusion injury in rats. Digestive diseases and sciences 2009;54:2568-2576.

6 Cursio R, Colosetti P, Gugenheim J: Autophagy and liver ischemia-reperfusion injury. BioMed research international 2015;2015:417590.

7 Lemasters JJ, Thurman RG: Reperfusion injury after liver preservation for transplantation. Annual review of pharmacology and toxicology 1997;37:327-338.

$>8$ Thompson CB: Apoptosis in the pathogenesis and treatment of disease. Science 1995;267:1456-1462.

$>9$ Kalimuthu S, Se-Kwon K: Cell survival and apoptosis signaling as therapeutic target for cancer: Marine bioactive compounds. International journal of molecular sciences 2013;14:2334-2354.

$>10$ Weinberg SE, Chandel NS: Targeting mitochondria metabolism for cancer therapy. Nature chemical biology 2015;11:9-15.

-11 Huang CY, Hsiao JK, Lu YZ, Lee TC, Yu LC: Anti-apoptotic pi3k/akt signaling by sodium/glucose transporter 1 reduces epithelial barrier damage and bacterial translocation in intestinal ischemia. Laboratory investigation; a journal of technical methods and pathology 2011;91:294-309.

12 Kim HJ, Joe Y, Kong JS, Jeong SO, Cho GJ, Ryter SW, Chung HT: Carbon monoxide protects against hepatic ischemia/reperfusion injury via ros-dependent akt signaling and inhibition of glycogen synthase kinase 3beta. Oxidative medicine and cellular longevity 2013;2013:306421.

13 Zhang R, Zhang L, Manaenko A, Ye Z, Liu W, Sun X: Helium preconditioning protects mouse liver against ischemia and reperfusion injury through the pi3k/akt pathway. Journal of hepatology 2014;61:1048-1055.

14 Sivakumar AS, Anuradha CV: Effect of galangin supplementation on oxidative damage and inflammatory changes in fructose-fed rat liver. Chemico-biological interactions 2011;193:141-148.

15 Benguedouar L, Lahouel M, Gangloff SC, Durlach A, Grange F, Bernard P, Antonicelli F: Ethanolic extract of algerian propolis and galangin decreased murine melanoma t. Anti-cancer agents in medicinal chemistry 2016;16:1172-1183.

16 Su L, Chen X, Wu J, Lin B, Zhang H, Lan L, Luo H: Galangin inhibits proliferation of hepatocellular carcinoma cells by inducing endoplasmic reticulum stress. Food and chemical toxicology : an international journal published for the British Industrial Biological Research Association 2013;62:810-816.

17 Ha TK, Kim ME, Yoon JH, Bae SJ, Yeom J, Lee JS: Galangin induces human colon cancer cell death via the mitochondrial dysfunction and caspase-dependent pathway. Experimental biology and medicine 2013;238:1047-1054.

18 Zhang F, Mao Y, Qiao H, Jiang H, Zhao H, Chen X, Tong L, Sun X: Protective effects of taurine against endotoxin-induced acute liver injury after hepatic ischemia reperfusion. Amino acids 2010;38:237-245.

19 Suo L, Kang K, Wang X, Cao Y, Zhao H, Sun X, Tong L, Zhang F: Carvacrol alleviates ischemia reperfusion injury by regulating the pi3k-akt pathway in rats. PloS one 2014;9:e104043.

20 Roberts RA, James NH, Cosulich SC: The role of protein kinase b and mitogen-activated protein kinase in epidermal growth factor and tumor necrosis factor alpha-mediated rat hepatocyte survival and apoptosis. Hepatology 2000;31:420-427. 


\section{Cellular Physiology Cell Physiol Biochem 2018;51:1354-1363 and Biochemistry \begin{tabular}{l|l|l|l} 
DOI: 10.1159/000495553 2018 The Author(s). Published by S. Karger AG, Basel \\
\hline
\end{tabular}

-21 Zhang YE, Wang JN, Tang JM, Guo LY, Yang JY, Huang YZ, Tan Y, Fu SZ, Kong X, Zheng F: In vivo protein transduction: Delivery of pep-1-sod1 fusion protein into myocardium efficiently protects against ischemic insult. Molecules and cells 2009;27:159-166.

22 Zhang H, Liu Y, Yan L, Du W, Zhang X, Zhang M, Chen H, Zhang Y, Zhou J, Sun H, Zhu D: Bone morphogenetic protein-7 inhibits endothelial-mesenchymal transition in pulmonary artery endothelial cell under hypoxia. Journal of cellular physiology 2018;233:4077-4090.

23 Ebringer L, Dobias J, Krajcvoic J, Polonyi J, Krizkova L, Lahitova N: Antimutagens reduce ofloxacin-induced bleaching in euglena gracilis. Mutation research 1996;359:85-93.

-24 Sivakumar AS, Viswanathan P, Anuradha CV: Dose-dependent effect of galangin on fructose-mediated insulin resistance and oxidative events in rat kidney. Redox report: communications in free radical research 2010;15:224-232.

25 Huang H, Chen AY, Rojanasakul Y, Ye X, Rankin GO, Chen YC: Dietary compounds galangin and myricetin suppress ovarian cancer cell angiogenesis. Journal of functional foods 2015;15:464-475.

26 Rosentreter D, Funken D, Reifart J, Mende K, Rentsch M, Khandoga A: Rip1-dependent programmed necrosis is negatively regulated by caspases during hepatic ischemia-reperfusion. Shock 2015;44:72-76.

27 Elias-Miro M, Jimenez-Castro MB, Rodes J, Peralta C: Current knowledge on oxidative stress in hepatic ischemia/reperfusion. Free radical research 2013;47:555-568.

28 Dhalla NS, Elmoselhi AB, Hata T, Makino N: Status of myocardial antioxidants in ischemia-reperfusion injury. Cardiovascular research 2000;47:446-456.

29 Granger DN: Role of xanthine oxidase and granulocytes in ischemia-reperfusion injury. The American journal of physiology 1988;255:H1269-1275.

-30 Anaya-Prado R, Toledo-Pereyra LH, Lentsch AB, Ward PA: Ischemia/reperfusion injury. The Journal of surgical research 2002;105:248-258.

31 Halliwell B, Gutteridge JM, Cross CE: Free radicals, antioxidants, and human disease: Where are we now? The Journal of laboratory and clinical medicine 1992;119:598-620.

32 Cetin C, Kose AA, Aral E, Colak O, Ercel C, Karabagli Y, Alatas O, Eker A: Protective effect of fucoidin (a neutrophil rolling inhibitor) on ischemia reperfusion injury: Experimental study in rat epigastric island flaps. Annals of plastic surgery 2001;47:540-546.

-33 Gurlek A, Celik M, Parlakpinar H, Aydogan H, Bay-Karabulut A: The protective effect of melatonin on ischemia-reperfusion injury in the groin (inferior epigastric) flap model in rats. Journal of pineal research 2006;40:312-317.

34 Yadav SS, Sindram D, Perry DK, Clavien PA: Ischemic preconditioning protects the mouse liver by inhibition of apoptosis through a caspase-dependent pathway. Hepatology 1999;30:1223-1231.

-35 Perry DK, Smyth MJ, Stennicke HR, Salvesen GS, Duriez P, Poirier GG, Hannun YA: Zinc is a potent inhibitor of the apoptotic protease, caspase-3. A novel target for zinc in the inhibition of apoptosis. The Journal of biological chemistry 1997;272:18530-18533.

-36 Yao Y, Huang C, Li ZF, Wang AY, Liu LY, Zhao XG, Luo Y, Ni L, Zhang WG, Song TS: Exogenous phosphatidylethanolamine induces apoptosis of human hepatoma hepg2 cells via the bcl-2/bax pathway. World journal of gastroenterology 2009;15:1751-1758.

-37 Jin S, Dai CL: Attenuation of reperfusion-induced hepatocyte apoptosis is associated with reversed bcl-2/bax ratio in hemi-hepatic artery-preserved portal occlusion. The Journal of surgical research 2012;174:298-304. 